Article

\title{
Liver-Derived Cell Transfection Model Efficacy for HBV Genotype B Replication/Transcription Is Determined by Complex Host Transcription Factor Network
}

\author{
Roxanne Hui-Heng Chong ${ }^{1,+}$, Atefeh Khakpoor $\left.{ }^{1,+}{ }^{(}\right)$, Theresa May-Chin Tan ${ }^{2}$, Seng-Gee Lim ${ }^{1}$ \\ and Guan-Huei Lee ${ }^{1,3, *}$ \\ 1 Department of Medicine, Yong Loo Lin School of Medicine, National University of Singapore, \\ Singapore 117549, Singapore; huihengc@hotmail.com (R.H.-H.C.); mdcatef@nus.edu.sg (A.K.); \\ mdclimsg@nus.edu.sg (S.-G.L.) \\ 2 Department of Biochemistry, Yong Loo Lin School of Medicine, National University of Singapore, \\ Singapore 117597, Singapore; bchtant@nus.edu.sg \\ 3 Department of Medicine, National University Hospital, Singapore 119074, Singapore \\ * Correspondence: mdcleegh@nus.edu.sg; Tel.: +65-90181914 \\ + These authors contributed equally to this work.
}

check for updates

Citation: Chong, R.H.-H.; Khakpoor, A.; Tan, T.M.-C.; Lim, S.-G.; Lee, G.-H. Liver-Derived Cell Transfection Model Efficacy for HBV Genotype B Replication/Transcription Is Determined by Complex Host Transcription Factor Network. Viruses 2021, 13, 524. https://doi.org/ $10.3390 /$ v13030524

Academic Editors: Angela L. Rasmussen and Juliet Morrison

Received: 18 February 2021

Accepted: 18 March 2021

Published: 22 March 2021

Publisher's Note: MDPI stays neutral with regard to jurisdictional claims in published maps and institutional affiliations.

Copyright: (c) 2021 by the authors. Licensee MDPI, Basel, Switzerland. This article is an open access article distributed under the terms and conditions of the Creative Commons Attribution (CC BY) license (https:/ / creativecommons.org/licenses/by/ $4.0 /)$.

\begin{abstract}
Background: Interaction between host transcription factors (TFs) and the viral genome is fundamental for hepatitis B virus (HBV) gene expression regulation. Additionally, the distinct interaction of the TFs' network with the HBV genome determines the regulatory effect outcome. Hence, different HBV genotypes and their variants may display different viral replication/transcription regulation. Due to the lack of an efficient infection model suitable for all HBV genotypes, the hepatoma cell transfection model is primarily used in studies involving non-D HBV genotypes and variants. Methods: We explored the transcriptome profile of host TFs with a regulatory effect on HBV in eight liver-derived cell lines in comparison with primary human hepatocytes (PHH). We further analyzed the suitability of these models in supporting HBV genotype B replication/transcription. Results: Among studied models, HC-04, as a result of the close similarity of TFs transcriptome profile to $\mathrm{PHH}$ and the interaction of specific TFs including HNF $4 \alpha$ and PPAR $\alpha$, showed the highest efficiency in regard to viral replication and antigen production. The absence of TFs expression in L02 transfection model resulted in its inefficiency in HBV replication/transcription. Conclusion: These observations help to better design studies on regulatory mechanisms involving non-D HBV genotypes and variants' gene expression and the development of more efficient therapeutical approaches.
\end{abstract}

Keywords: hepatitis B virus; transcription factor; transfection model; genotype B

\section{Introduction}

Hepatitis B virus (HBV), the causative agent for chronic HBV infection (CHB), is a major global health risk factor [1]. Similar to other viruses (HPV, EBV, etc.) [2,3], HBV gene expression regulation is an interplay between viral genome and host factors. Accumulating evidence suggests that precise recruitment of host transcription factors (TFs) to distinct regulatory sites on viral covalently closed circular DNA (cccDNA) leads to viral gene expression regulation [4-7]. HBV genome cloning and mapping of viral transcripts have led to a comprehensive understanding of the promoters (pre-core/core, $\mathrm{X}$, pre-S1, and pre-S2/S promoters) and enhancers (Enh) I and II regulatory sites. These sites control the synthesis of viral transcripts including the replication intermediate, pre-genomic RNA (pg-RNA) in cooperation with host TFs $[1,5,8,9]$.

Host TFs tropism is either restricted to hepatocytes (liver enriched TFs) or expressed in other cell types, which are categorized as ubiquitous TFs [5,7]. Past studies have shown that liver enriched TFs, specifically, the hepatocyte nuclear factor family (HNF) play a fundamental role in HBV replication/transcription regulation [5-8]. Enhanced 
activities from preS1, preS2/S, core promoter, and Enh- II as a result of binding of liver enriched TFs, including HNF1 $\alpha, \mathrm{HNF} 3 \alpha$ and HNF4 $\alpha$ were observed using hepatoma cells [9-11]. Apart from liver enriched TFs, several ubiquitous TFs do play crucial roles in HBV replication/transcription [5]. SP-1 and NF1 binding to the S promoter are essential for promoter optimal activity $[6,12]$. Studies by Ori et al. have established the positive regulatory role of NF1 on pg-RNA synthesis through binding to Enh-I $[10,13]$.

$\mathrm{HBV}$ gene expression regulation is modulated by the distinct site of interaction and the expression level of TFs. Hence, possible alterations in the interaction sites among HBV genotypes and their variants as a result of mutations may lead to different regulatory effects of TFs on each genotype [5-8]. Despite the discovery of HBV entry receptor [14] and establishment of a highly efficient in vitro infection model supporting HBV genotype D [15], studies on non-D HBV genotypes and variants are hampered by the lack of an existing high titer viral source for efficient infection in an existing in-vitro model. Hence, liver-derived cell transfection models are the preferred approach in these studies.

Here, we investigate the transcriptome and proteome profile of selected liver enriched and ubiquitous TFs with regulatory roles in HBV gene expression, across eight established human liver-derived cell lines in comparison with primary human hepatocytes (PHH). We further studied how host TFs expression regulates HBV genotype B replication and gene expression in transfection models either with hepatocellular carcinoma-derived lines (HCC) (HepG2, HepG2-hNTCP, Huh-7, HuH-6, and JHH-4) or immortalized cells of human hepatocyte (L02, HC-04, and THLE-2) origin.

\section{Materials and Methods}

\subsection{Cell Culture}

PHH batches from 3 different donors (Gentest ${ }^{\mathrm{TM}}$ plateable cryohepatocytes, BD Biosciences, USA) were negative for human immunodeficiency virus (HIV), $\mathrm{HBV}$, and hepatitis $\mathrm{C}$ virus (HCV). Cells were cultured on BioCoat collagen I plate (Corning) using Gentest ${ }^{\mathrm{TM}}$ Plating Medium supplemented with $10 \%$ fetal bovine serum (FBS).

HCC cell lines (HepG2, Huh-7, HuH-6, JHH-4 [16-19], HepG2-hNTCP [15], HepG2.2.15) and immortalized human hepatocyte lines (L02, HC-04, THLE-2) were incubated at $37^{\circ} \mathrm{C}$ under $5 \% \mathrm{CO}_{2}$ in media as described in Table 1.

\subsection{TFs Transcriptome Analysis}

Cells were harvested at $48 \mathrm{~h}$ post-seeding and subjected to:

1. RNA extraction and cDNA synthesis. Total RNA was extracted using RNeasy Mini Kit (Qiagen, Hilden, Germany) and lysates were treated with RNase-free DNase I (New England Biolabs) before proceeding to total RNA reverse transcription with oligo $(\mathrm{dT})_{20}$ SuperScript ${ }^{\circledR}$ III First-Strand Synthesis System (Invitrogen, Thermo Fisher Scientific) following the manufacturer's instructions.

2. $\quad$ Real-time PCR. Real-time PCR was performed using the QuantiTect $S Y B R^{\circledR}$ Green PCR Kit (Qiagen) on the ABI prism 7000 sequence detection system or QuantStudio 6 Flex Real-Time PCR System (Applied Biosystems, Thermo Fisher Scientific). Table 2 summarizes the primer sequences used. Endogenous $\beta$-actin transcript level [21] was used for normalization. Relative mRNA expression levels were calculated using $\Delta \Delta \mathrm{Ct}$ method. The hierarchical clustering analysis was based on the mean of log2-transformed data using the complete linkage method with Euclidean distance measure. Heatmap was generated using R software. 
Table 1. Characteristics of cell lines.

\begin{tabular}{|c|c|c|c|c|}
\hline No. & Cell Lines & Source of the Cells & Case History & Culture Medium \\
\hline 1 & HepG2 & ATCC & $\mathrm{HCC}$ & $\begin{array}{l}\text { DMEM supplemented with } 4 \mathrm{mM} \\
\text { L-glutamine, } 1 \mathrm{mM} \text { sodium pyruvate, } 10 \% \\
\text { FBS, } 100 \mathrm{U} / \mathrm{mL} \text { penicillin and } 100 \mu \mathrm{g} / \mathrm{mL} \\
\text { streptomycin }\end{array}$ \\
\hline 2 & Huh-7 & RIKEN Cell Bank & $\mathrm{HCC}$ & Same as HepG2 cells \\
\hline 3 & HuH-6 & $\begin{array}{c}\text { Japan Health Sciences } \\
\text { Foundation }\end{array}$ & $\mathrm{HCC}$ & Same as HepG2 cells \\
\hline 4 & JHH-4 & $\begin{array}{c}\text { Japan Health Sciences } \\
\text { Foundation }\end{array}$ & $\mathrm{HCC}$ & Same as HepG2 cells \\
\hline 5 & L02 & $\begin{array}{l}\text { Prof. Tao Zhu from } \\
\text { University of Science } \\
\text { and Technology of } \\
\text { China }\end{array}$ & $\begin{array}{l}\text { Immortalized human } \\
\text { hepatocyte cell line }\end{array}$ & Same as HepG2 cells \\
\hline 6 & $\mathrm{HC}-04$ & BEI Resources & $\begin{array}{l}\text { Immortalized human } \\
\text { hepatocyte cell line }\end{array}$ & $\begin{array}{c}\text { DMEM/F12 medium (1:1) supplemented } \\
\text { with } 15 \mathrm{mM} \text { HEPES, } 1.5 \mathrm{~g} / \mathrm{L} \text { sodium } \\
\text { bicarbonate, } 2.5 \mathrm{mM} \text { L-glutamine, } 100 \mathrm{U} / \mathrm{mL} \\
\text { penicillin, } 100 \mu \mathrm{g} / \mathrm{mL} \text { streptomycin and } 10 \% \\
\text { FBS }\end{array}$ \\
\hline 7 & THLE-2 & ATCC & $\begin{array}{l}\text { Simian virus } 40 \text { (SV40) large } \\
\text { T antigen-immortalized } \\
\text { normal liver epithelial cells }\end{array}$ & $\begin{array}{l}\text { BEGM BulletKit excluding GA-1000 and } \\
\text { epinephrine aliquots with additional } \\
5 \mathrm{ng} / \mathrm{mL} \text { EGF, } 70 \mathrm{ng} / \mathrm{mL} \\
\text { phosphoethanolamine, } 100 \mathrm{U} / \mathrm{mL} \text { penicillin, } \\
100 \mu \mathrm{g} / \mathrm{mL} \text { streptomycin and } 10 \% \text { FBS. }\end{array}$ \\
\hline 8 & HepG2-hNTCP & $\begin{array}{l}\text { Prof. Stephan Urban } \\
\text { from University } \\
\text { Hospital Heidelberg }\end{array}$ & $\begin{array}{c}\text { HepG2 cells transduced with } \\
\text { human sodium-taurocholate } \\
\text { co-transporter polypeptide } \\
\text { (hNTCP) }\end{array}$ & $\begin{array}{l}\text { Same as HepG2 cells } \\
\text { selection: } 5 \mu \mathrm{g} / \mathrm{mL} \text { puromycin }\end{array}$ \\
\hline 9 & HepG2.2.15 & [20] & $\begin{array}{l}\text { HepG2 cells transfected with } \\
\text { plasmids containing two } \\
\text { head-to-tail dimers of the } \\
\text { HBV genotype D genome }\end{array}$ & $\begin{array}{c}\text { Same as HepG2 cells } \\
\text { Selection: } 200 \mu \mathrm{g} / \mathrm{mL} \text { G418 }\end{array}$ \\
\hline
\end{tabular}

DMEM: Dulbecco's Modified Eagle's medium; FBS: fetal bovine serum; BEGM: bronchial epithelial cell growth medium; GA: gentamycin/amphotericin; EGF: epidermal growth factor.

Table 2. Primers used for transcription factors (TFs).

\begin{tabular}{|c|c|c|c|c|c|}
\hline No. & Target & Forward Primer $\left(5^{\prime}-3^{\prime}\right)$ & Reverse Primer $\left(5^{\prime}-3^{\prime}\right)$ & $\begin{array}{c}\text { Annealing } \\
\text { Temperature } \\
\left({ }^{\circ} \mathrm{C}\right)\end{array}$ & $\begin{array}{l}\text { Amplicon } \\
\text { Size (bp) }\end{array}$ \\
\hline 1 & HNF1 $\alpha$ & CACGCCACCCATCCTCAAAG & CTTGACCATCTTCGCCACACG & 55 & 118 \\
\hline 2 & HNF1 $\beta$ & ACAATCCACTCTCAGGAGGC & GAGGTTCCTTGTCTCCСACC & 60 & 123 \\
\hline 3 & $\mathrm{HNF} 3 \alpha$ & CTACTACGCAGACACGCAGGAG & GTCATGTTGCCGCTCGTAGTC & 55 & 129 \\
\hline 4 & HNF3 $\beta$ & CTCACAGGCTCAACTCGGG & TCСССТTCAGСТСТСССAGG & 60 & 128 \\
\hline 5 & HNF3 $\gamma$ & TCTGGTGACACTTCACTTGTCC & GTACCCCGTGGATCAACACC & 60 & 103 \\
\hline 6 & $\mathrm{HNF} 4 \alpha$ & ACGACACGTCCCCATCAGAAG & ACCGTAGTGTTTGCCCGTGG & 55 & 107 \\
\hline 7 & $\mathrm{HNF} 4 \gamma$ & GGGTCAAGCACTGACATAAACG & ACAGTGCCACCTGATCATCC & 60 & 148 \\
\hline 8 & $\operatorname{PPAR} \alpha$ & CGCAAACTTGGACCTGAACG & TCCATACGCTACCAGCATCCC & 60 & 115 \\
\hline 9 & $\mathrm{RXR} \alpha$ & GACGGAGCTTGTGTCCAAGAT & AGTCAGGGTTAAAGAGGACGAT & 55 & 89 \\
\hline 10 & $\mathrm{C} / \mathrm{EBP} \alpha$ & ACAAGAACAGCAACGAGTACCG & GGTCATTGTCACTGGTCAGCTC & 55 & 132 \\
\hline 12 & $\mathrm{AP} 1 / \mathrm{cJun}$ & GCGCAGCCCAAACTAACCTC & AGCCATAAGGTCCGCTCTCG & 60 & 124 \\
\hline 13 & ATF2 & ACACAACTCCACAGACCCAAAG & GAAGCTGCTGCTCTATTTCGC & 55 & 109 \\
\hline 16 & NF1 & GCCTTTAACACCCGCGTACAG & TTCCAAGTCGGCTCAACTGC & 55 & 126 \\
\hline 18 & SP1 & AGTTCCAGACCGTTGATGGG & GTTTGCACCTGGTATGATCTGT & 60 & 118 \\
\hline 19 & STAT3 & СTCTACAGTGACAGCTTCCC & CCCAGGAGATTATGAAACAC & 55 & 125 \\
\hline
\end{tabular}




\subsection{TFs Proteome Analysis}

Forty-eight hours post-seeding, nuclear protein was extracted and subjected to SDS polyacrylamide gel electrophoresis followed by transfer to nitrocellulose membranes. Membranes were blocked and probed with primary antibodies (Table 3) followed by horseradish peroxidase-conjugated secondary antibodies probing, goat anti-mouse $\mathrm{IgG}$, goat anti-rabbit IgG (Thermo Fisher Scientific, MA, USA), and donkey anti-goat IgG (Santa Cruz Biotechnology, TX, USA). Protein bands were visualized using enhanced chemiluminescence (ECL) by Advansta ECL kit. Quantitative analysis of the signal intensity was performed using Quantity One 1-D Analysis Software (Bio-Rad Laboratories, CA, USA).

Table 3. Primary antibodies for Western blot.

\begin{tabular}{cccc}
\hline No. & Target & Source & Manufacturer \\
\hline 1 & HNF1 $\alpha$ & Rabbit & Cell Signaling Technology, \#89670 \\
2 & HNF3 $\alpha$ & Rabbit & Cell Signaling Technology, \#58613 \\
3 & HNF3 $\beta$ & Rabbit & Cell Signaling Technology, \#8186 \\
4 & HNF3 $\gamma$ & Goat & Santa Cruz Biotechnology, sc-5361 \\
5 & HNF4 $\alpha$ & Mouse & Abcam, ab41898 \\
6 & PPAR $\alpha$ & Mouse & Santa Cruz Biotechnology, sc-398394 \\
7 & RXR $\alpha$ & Rabbit & Cell Signaling Technology, \#5388 \\
8 & C/EBP $\alpha$ & Rabbit & Abcam, ab40764 \\
9 & $\beta$-actin & Mouse & Santa Cruz Biotechnology, sc-4778 \\
\hline
\end{tabular}

\subsection{Transient Transfection of Full-Length HBV DNA Genome}

A full-length HBV clone was generated from a genotype B HBeAg-negative reactivation serum sample according to the method described by Günther et al. [22]. Linear HBV monomers were prepared from the plasmid by BspQI (New England Biolabs, MA, USA) digestion and gel purification using QIAquick Gel Extraction Kit (Qiagen, Hilden, Germany). Transfection was carried out using Effectene (Qiagen, Hilden, Germany) or X-tremeGENE HP DNA Transfection Reagent (Roche, Switzerland) with 750 ng HBV linear DNA at $24 \mathrm{~h}$ post-seeding. Cells were co-transfected with $250 \mathrm{ng}$ green fluorescence protein (GFP) expression vector pCMV6-AC-GFP (OriGene Technologies, MD, USA).

\subsection{HBV Pre-Genomic RNA (pg-RNA) Analysis}

Seventy-two hours post-transfection, RNA extraction, and cDNA synthesis were carried out and pg-RNA was quantified through real-time PCR as described in the transcriptome analysis section. Amplification was performed using QuantiNova SYBR Green PCR Kit (Qiagen, Hilden, Germany) with pg-RNA specific primers: Forward primer 5'-CTT TTG GAG TGT GGA TTC GC-3' and reverse primer 5'-GCG AGG GAG TTC Quant Inova TTC TA- $3^{\prime}$.

\subsection{HBV DNA Quantification}

\subsubsection{Intracellular Core-Associated DNA}

Transfected cells were washed and lysed in $50 \mathrm{mM}$ Tris- $\mathrm{HCl} \mathrm{pH}$ 7.4, $1 \mathrm{mM}$ EDTA, and $1 \%$ Nonidet P-40. Nuclei were pelleted and the supernatant was adjusted to $10 \mathrm{mM} \mathrm{MgSO}_{4}$ and treated with $100 \mu \mathrm{g} / \mathrm{mL}$ DNase I for $30 \mathrm{~min}$ at $37^{\circ} \mathrm{C}$. The reaction was stopped by the addition of EDTA at a final concentration of $25 \mathrm{mM}$ [23].

\subsubsection{Extracellular HBV DNA}

Viral particles were precipitated from culture supernatant overnight at $4{ }^{\circ} \mathrm{C}$ using $10 \%$ polyethylene glycol 8000 (PEG 8000). The precipitates were collected and re-suspended in Tris-EDTA (TE) buffer. Residual transfection DNA was removed by DNase I treatment at $37^{\circ} \mathrm{C}[23,24]$. DNA was then extracted using the QIAamp DNA Blood Mini Kit (Qiagen, Hilden, Germany). 


\subsubsection{HBV DNA Copy Number Measurement}

TaqMan Universal PCR master mix (Applied Biosystems, Thermo Fisher Scientific, MA, USA) was used as previously described [25] with minor modifications in QuantStudio 6 Flex Real-Time PCR System. Forward and reverse primers were 5'-CCG TCT GTG CCT TCT CAT CTG- ${ }^{\prime}$ and 5'-AGT CCA AGA GTY CTC TTA TGY AAG ACC TT-3', respectively, and the fluorescent probe was $5^{\prime}$-FAM-CCG TGT GCA CTT CGC TTC ACC TCT GC-TAMRA- $3^{\prime}$. Serially diluted DNA plasmids, containing a single copy of full-length HBV DNA, with the identical sequence as the HBV clone used for transfection, were used as quantification standards.

\section{7. $\mathrm{HBV}$ Core Antigen ( $\mathrm{HBc} \mathrm{Ag}$ ) Quantification}

At $72 \mathrm{~h}$ post-transfection, cells were fixed and permeabilized with Cytofix/Cytoperm solution (BD Bioscience, CA, USA). Cells were incubated with mouse anti-HBcAg (Abcam, $\mathrm{UK}$ ) followed by an Alexa Fluor 647 goat anti-mouse IgG, 2nd Ab (Invitrogen, Thermo Fisher Scientific, MA, USA). Cells were fixed in 1\% paraformaldehyde prior to flow cytometry analysis using the BD LSR Fortessa. Data were analyzed using FlowJo Software (FlowJo, LLC, Oregon, USA).

\subsection{Hepatitis B Surface Antigen ( $H B s A g)$ Analysis}

Secreted HBsAg was quantified using Monolisa HBsAg ULTRA assay (Bio-Rad Laboratories, CA, USA). HBsAg levels were detected semi-quantitatively by measuring the optical density at $450 \mathrm{~nm}$ according to the manufacturer's instructions.

\subsection{Statistical Analysis}

Quantitative variables were analyzed using the Student's $t$-test. Correlation analysis was carried out using the Pearson correlation coefficient. All statistical analysis was performed using GraphPad Prism software, version 8 (San Diego, CA, USA). A $p$-value of less than 0.05 was considered statistically significant.

\section{Results}

3.1. Heterogeneous Gene Expression Profile in Liver Enriched TFs among Liver-Derived Cell Lines

To understand the suitability of liver-derived cell transfection models for HBV genotype B replication/transcription, we first determined the transcriptome profile of selected liver enriched TFs including the HNF family: HNF1(HNF1 $\alpha$, HNF1 $\beta$ ), HNF3 $(\mathrm{HNF} 3 \alpha, \mathrm{HNF} 3 \beta, \mathrm{HNF} 3 \gamma), \mathrm{HNF} 4$ (HNF4 $\alpha, \mathrm{HNF} 4 \gamma$ ) along with CCAAT binding protein- $\alpha$ $(\mathrm{C} / \mathrm{EBP} \alpha)$, peroxisome proliferator-activated receptor $\alpha(\mathrm{PPAR} \alpha)$ and retinoid $\mathrm{X}$ receptor $\alpha(R X R \alpha)$ in HCC-derived hepatoma cells and immortalized human hepatocyte cells in comparison with $\mathrm{PHH}$.

In the immortalized human hepatocyte line, HC-04, the majority of TFs including HNFs (HNF3 $\beta, \mathrm{HNF} 3 \gamma$, and HNF4 $\gamma$ ), $\mathrm{C} / \mathrm{EBP} \alpha$, and RXR $\alpha$ were expressed at similar levels to PHH. However, HNF3 $\alpha, \mathrm{HNF} 4 \alpha$, and PPAR $\alpha$ showed 2 to 8 -fold enhanced mRNA expression relative to $\mathrm{PHH}$ (Figure 1A).

HNF1 $\alpha, H N F 3 \beta$ and HNF4 $\alpha$ expression levels were enhanced 2 to 6-fold in HCCderived HepG2, Huh-7, HuH-6, and HepG2-hNTCP cells in comparison with PHH (Figure 1A; Supplementary Materials, Figure S1A), while HNF3 $\alpha$ and C/EBP $\alpha$ showed 10 to 12-fold enhanced expression in HuH-6 line (Figure 1A). The majority of studied liver enriched TFs were not expressed or expressed at significantly lower levels in L02 and THLE-2 cells (Figure 1A). 
(A)
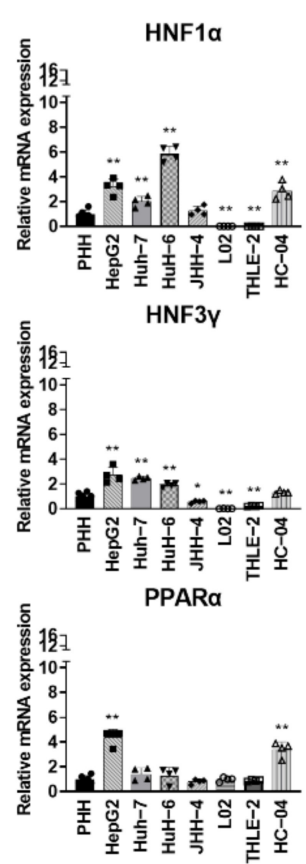

(B)
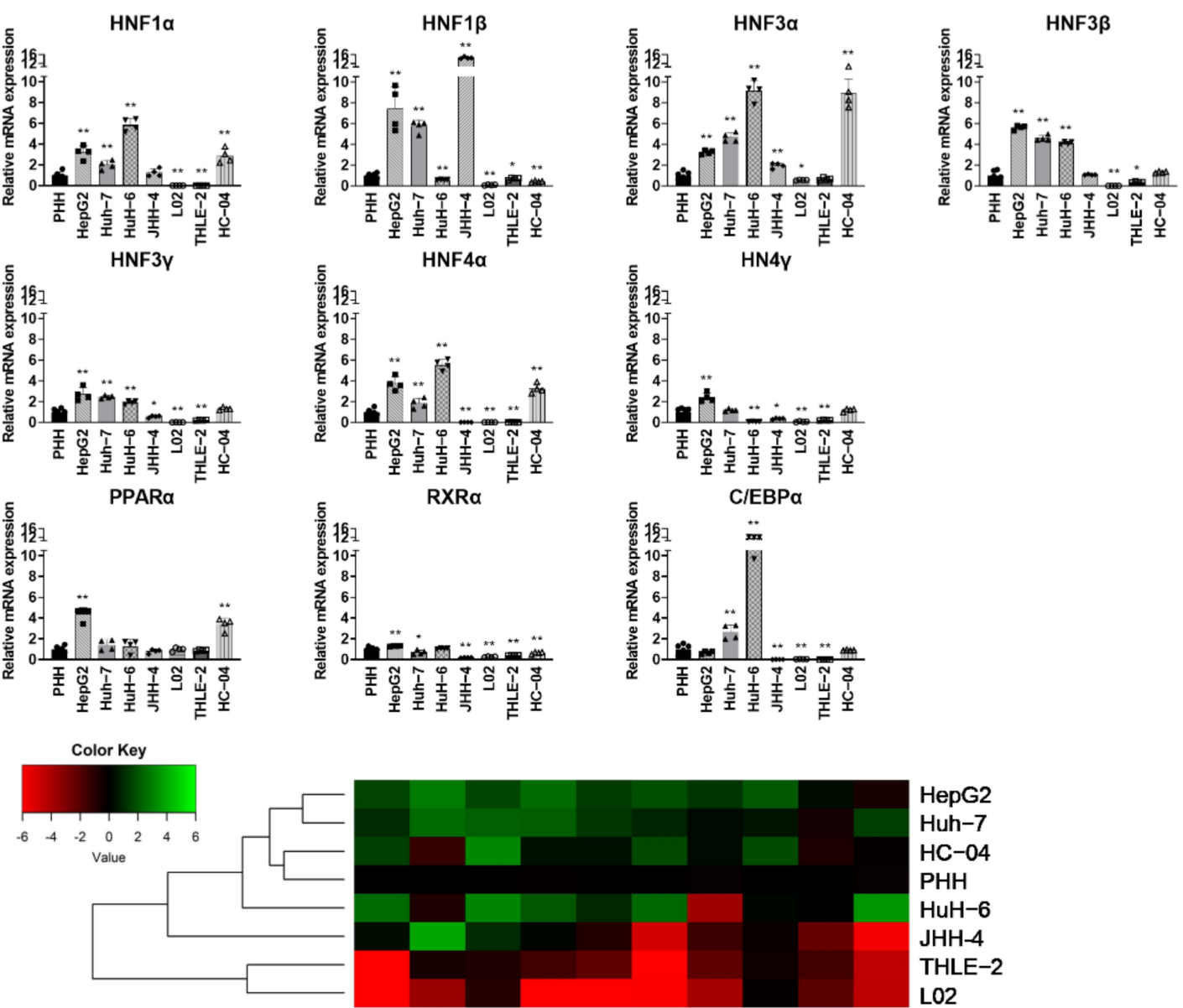

(C)
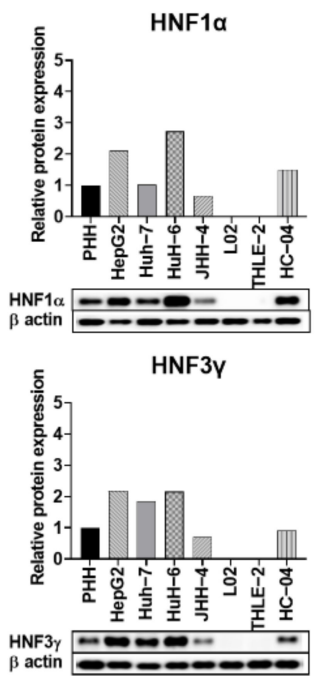

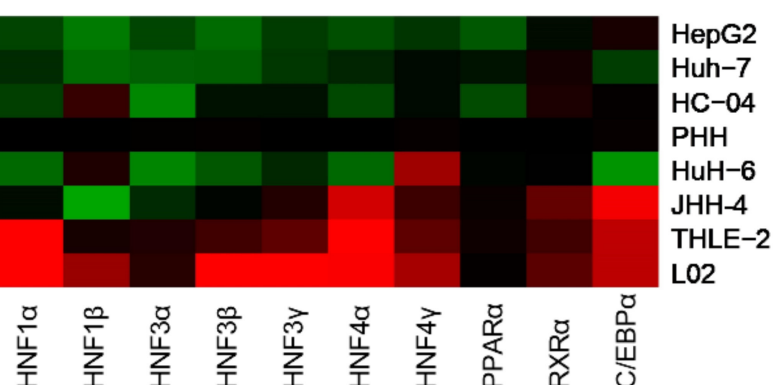

HNF3a
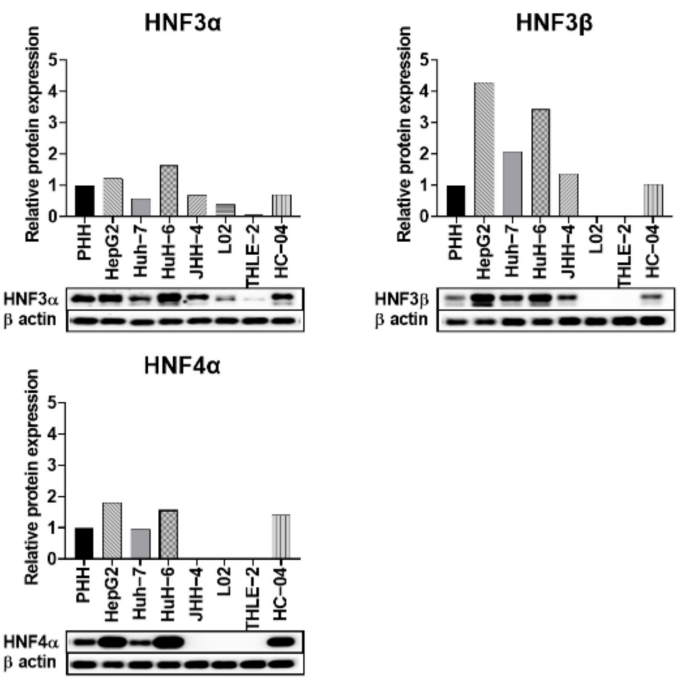

Figure 1. Liver enriched TFs expression level among liver-derived cell lines. (A) Relative mRNA expression of liver enriched TFs to primary human hepatocytes (PHH). Each data bar represents the mean + SD from two independent experiments, each done in duplicates. The values for PHH are from 3 different donors. ${ }^{*} p<0.05,{ }^{* *} p<0.01, t$-test done by comparing each of the cell lines to PHH. (B) Hierarchical clustering of mRNA expression of liver enriched TFs among hepatoma cell lines relative to PHH. (C) Relative protein expression of liver enriched TFs. $\beta$-actin was used as an internal control. 
Figure 1B shows the dendrogram clustering of liver enriched TFs, which displays a close similarity between PHH and HC-04, followed by Huh-7, HepG2, and HuH-6. However, THLE-2 and L02 clustered furthest from PHH (Figure 1B).

We further investigated the protein expression of the HNF family of $\mathrm{TF}$, in which enhanced mRNA expression level was observed in many cell lines (Figure 1C). Confirming our observations at the transcriptome level, HC-04 has a similar protein expression level compared to PHH (Figure 1C). Low or no expression of selected TFs was observed in L02 and THLE-2 cell lines. Among HCC-derived cell lines, HuH-6, Huh-7 and HepG2 showed a slight increase in TF protein expression relative to PHH except for HNF3 $\beta$, which showed 2 to 4 -fold enhanced expression in HepG2 and Huh-6 cells (Figure 1C).

These observations indicate that the cell lines studied showed heterogeneous patterns of expression of liver enriched TFs at protein and transcript levels. This differential expression level may in turn lead to differences in efficiency in supporting HBV replication/transcription.

\subsection{Ubiquitous Transcription Factors Are Expressed at Similar Levels to PHH among Liver-Derived Cell Lines}

As mentioned, apart from liver enriched TFs, several ubiquitous TFs are known to play a regulatory role in HBV replication/transcription. Hence, we next investigated the mRNA expression levels of several ubiquitous TFs including NF1, activating transcription factor (ATF), STAT3, AP1, and SP1. In HC-04 cells, these were expressed at similar level relative to PHH in HC-04 (Figure 2A), except for NF1. In HCC-derived HepG2, Huh-7 and $\mathrm{HuH}-6$ as well as JHH-4 cells, the ubiquitous TFs, STAT3, and SP1 were expressed at similar levels as PHH, while slight increases in ATF and AP1 were observed (Figure 2A). NF1, which plays a key role in S promoter activity, showed an enhanced expression (more than 3-fold) in all cell lines except in HuH-6. Unlike liver enriched TFs, in L02 and THLE2 cells, ubiquitous TFs were expressed either at similar levels as PHH or enhanced by approximately 6-fold in the case of NF1 (Figure 2A). In HepG2-hNTCP cells, NF1 showed 4-fold increased expression relative to PHH while STAT3 and AP1 are expressed at similar levels as PHH (Supplementary Materials, Figure S1B).

(A)
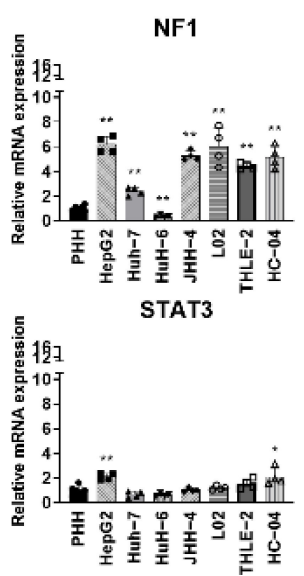

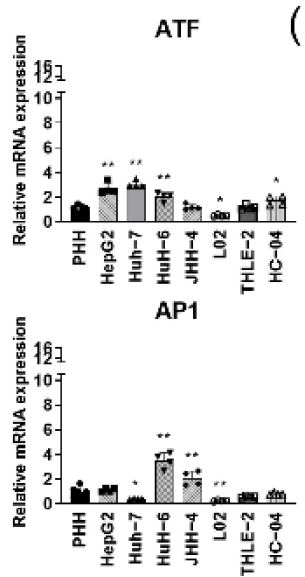

Sp1
(B)

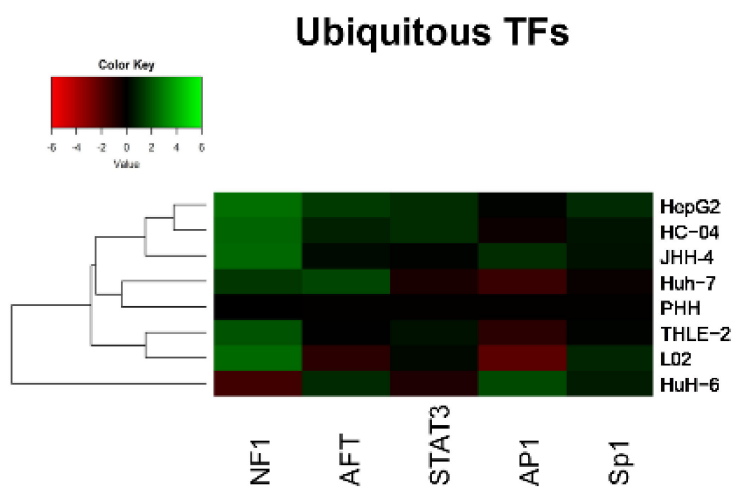

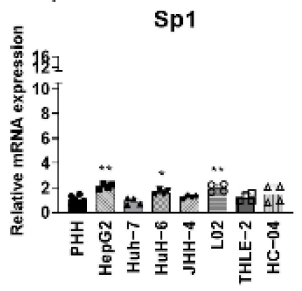

Figure 2. Ubiquitous TFs transcriptome profile. (A) Ubiquitous TFs mRNA expression quantification (relative to PHH). Each data bar represents the mean + SD from two independent experiments, done in duplicates. PHH values represent 3 donors. ${ }^{*} p<0.05,{ }^{* *} p<0.01, t$-test, by comparing each of the cell lines to PHH. (B) Hierarchical clustering of relative mRNA expression of ubiquitous TFs in liver-derived cells. 
Dendrogram clustering revealed a close similarity between Huh-7 and PHH. THLE-2 and L02 are clustered together and further from $\mathrm{PHH}$ while HuH-6 is clustered furthest from PHH. HC-04 and HepG2 showed more similarity in ubiquitous TF transcriptome profiles.

Unlike the heterogeneous expression profile observed in liver enriched TFs, ubiquitous TFs are expressed among all liver-derived cell lines.

\subsection{HBV Genotype B Liver-Derived Cell Transfection Models}

As mentioned, the lack of an efficient in vitro infection model, which supports all HBV genotypes infection has led to the dependence on the transfection model approach for non-D HBV genotype studies. Here, we investigated the suitability of several liver-derived cell lines for supporting HBV genotype B replication/transcription. HCC derived and immortalized human hepatocyte-derived cells were co-transfected with the full-length HBV genotype B genome and a plasmid encoding GFP ORF (for transfection efficiency assessment). We then analyzed HBV replication/transcription efficiency in each cell line and examined possible correlations with expression levels of the assessed TFs.

3.3.1. HBV Replication in Liver-Derived Cell Lines Is Associated Particularly with HNF $4 \alpha$ Expression

At $72 \mathrm{~h}$ post-transfection, the expression levels of viral pg-RNA, as well as the levels of HBV intracellular and extracellular DNA, were determined. These were then compared with those from HepG2.2.15 cells, which carry the HBV genotype D genome. To enable meaningful comparison, all data were normalized to the transfection efficiency of each cell line used.

High quantities of pg-RNA were detected (>20-fold higher than HepG2.2.15) in HC-04 cells. pg-RNA expression was 3 to 8-fold higher than HepG2.2.15 in HCC-derived HepG2, HuH-6, and Huh-7 cells. No pg-RNA was detected in JHH-4 and L02 (Figure 3A).

(A)

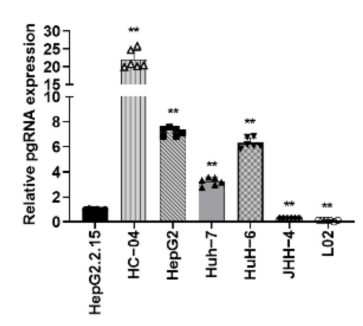

(D)

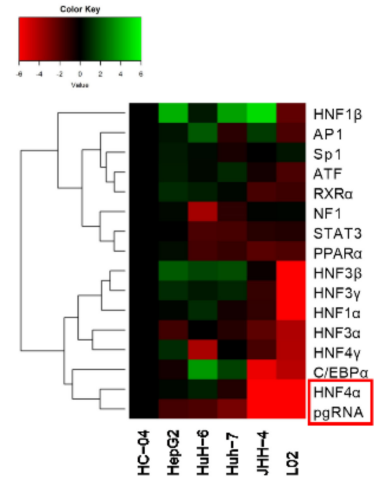

(B)

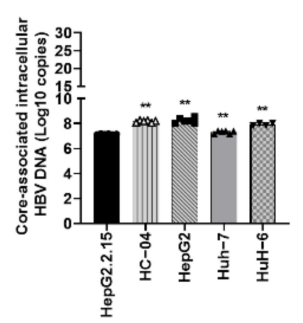

(E)

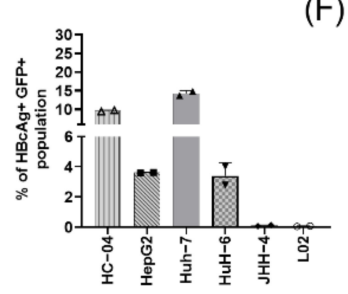

(C)

(F)
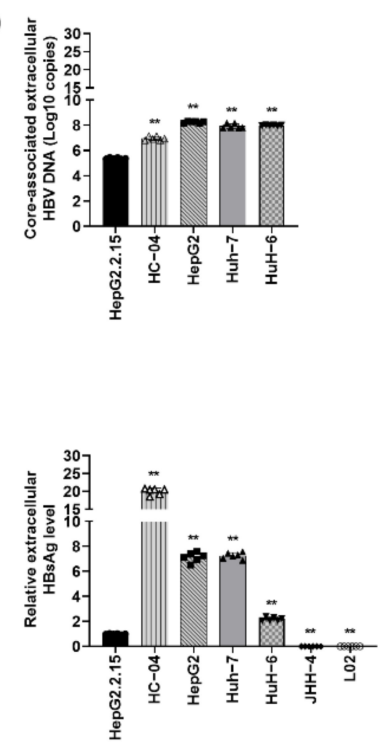

Figure 3. Efficiency of liver-derived cell transfection models in supporting hepatitis B virus (HBV) genotype B replication and gene expression. (A) Relative pg-RNA expression to HepG2.2.15 among the liver-derived cell transfection models at $72 \mathrm{~h}$ post-transfection. ${ }^{* *} p<0.01$, T-test, by comparing each of the cell lines to HepG2.2.15. Core-associated intracellular (B) and extracellular HBV DNA (C) in cell lines with detectable pg-RNA expression level. (D) Hierarchy clustering analysis of relative mRNA expression of host TFs and viral pg-RNA across transfection models (E) The percentage of $\mathrm{HBcAg}^{+}$ $\mathrm{GFP}^{+}$population measured by FACS analysis. (F) Secreted HBsAg in the supernatant of transfected cells measured by ELISA. Each data bar represents the average + SD from triplicate samples with two technical replicates. The relative HBsAg expression and $p$-value were calculated by comparing each of the cell lines to HepG2.2.15. 
Next, we measured core-associated extra- and intracellular viral DNA in cell lines with detectable pg-RNA synthesis. Despite the observed differences in pg-RNA expression level between HC-04 and HCC-derived hepatoma cells, similar levels of viral DNA were detected, that is, 6 to 8-fold higher than HepG2.2.15 (Figure 3B,C).

Hierarchical clustering was carried out to examine the correlation (if any) between pg-RNA production and the expression of host TFs. Figure 3D shows that pg-RNA is closely clustered with liver enriched TFs, specifically HNF $4 \alpha$, suggesting that pg-RNA expression level is highly dependent on HNF4 $\alpha$. Moreover, it was evident that there was closer clustering between the liver enriched TFs than between the ubiquitous TFs and pg-RNA. This is consistent with the fundamental regulatory role of liver enriched TFs in pg-RNA synthesis.

\subsubsection{Differential Expression of HBV Genotype B Antigens among Liver-Derived Cell Transfection Models}

Multiple studies have shown that TFs regulate HBV transcription through binding to the core and preS/S promoters on cccDNA. Hence, viral core antigen and HBV surface antigen production at $72 \mathrm{~h}$ post-transfection were measured and compared to that of HepG2.2.15 cells.

Intracellular $\mathrm{HBcAg}$ expression was determined in a population of cells co-expressing $\mathrm{HBcAg}$ and GFP (HBcAg+GFP+) using flow cytometry analysis. Ten to fifteen percent of cells were positive for HBcAg and GFP in HC-04 and HCC-derived hepatoma Huh-7 cells (Figure 3E). Lower HBcAg expressions were observed for HuH-6 and HepG2 cells. There was no HBcAg expression in JHH-4 and L02 cells (Figure 3E).

HC-04, HepG2, Huh-7, and HuH-6 cells all showed significantly high levels of HBsAg expression after transfection when compared to HepG2.2.15 cells. The highest expression was observed in HC-04 cells with a 20-fold increase compared to HepG2.2.15 cells. As expected, HBsAg expression was not detected in JHH-4 and L02 cells (Figure 3F).

Collectively, these results suggest that some of the cell lines are not able to support the production of HBV genotype B viral antigens, and hence, are not suitable as transfection models.

\section{Discussion}

The ability of liver-derived cell transfection models to support non-D HBV genotypes and related variants' replication/transcription is greatly influenced by the expression of transcription factors and the existence of specific TF networks.

This study unraveled the different fitness of the liver-derived cell lines for HBV genotype B replication/transcription. This is due to TFs transcriptome profile heterogeneity, with the best outcomes dependent on the degree of similarity to the profile of $\mathrm{PHH}$.

Our results suggest that the HC-04 transfection model is the most competent for HBV genotype B replication and antigen production. HC-04 cells displayed the most similar liver enriched TFs transcriptome profile to $\mathrm{PHH}$, indicating that this similarity is a key determining factor in efficient HBV replication and viral antigen production. Several HCC-derived cells with less similarity to PHH were also capable of supporting pg-RNA and viral antigen production, albeit at a lower efficiency compared to HC-04 cells. These include Huh-7, HepG2, and HuH-6 cells.

Our study further validates the fundamental role of HNF $4 \alpha$ expression in HBV genotype B replication (pg-RNA synthesis). HNF4 $\alpha$ clustered closest to pg-RNA, which suggests its expression directly controls pg-RNA synthesis. In JHH-4 and L02 models, the lack of $\mathrm{HNF} 4 \alpha$ expression resulted in the inability of these cells to support pg-RNA and viral antigen production. Similarly, lower levels of HNF4 $\alpha$ in the Huh-7 model led to lower pg-RNA production. Besides HNF4 $\alpha$ expression, pg-RNA production is known to be regulated by the interaction of multiple TFs. PPAR $\alpha$ and HNF $4 \alpha$ interaction has been demonstrated to have an additive effect on pg-RNA synthesis, where the over-expression of PPAR $\alpha$ and HNF4 $\alpha$ in non-hepatic cell lines was sufficient to increase pg-RNA expression. Similarly, over-expression of PPAR $\alpha$ in Huh-7 leads to an increased level of pg-RNA 
production [6-8]. HNF3 $\beta$ however, is known to decrease pg-RNA synthesis via interfering with RNA elongation $[5,6]$. Thus, the poor efficacy of pg-RNA production in Huh-7, HepG2, HuH- 6 cells when compared to HC-04 could be due to the higher expression of HNF3 $\beta$ in these cells. Overall, we conclude that HC-04 efficacy in pgRNA production is the result of the augmented expression of PPAR $\alpha$ and $\mathrm{HNF} 4 \alpha$, their interaction, and the absence of the inhibitory effects of HNF3 $\beta$.

Our observations also show the crucial role of a specific TF network in efficient viral antigen production. In HC-04 cells, a significant increase in mRNA expression was observed only in HNF3 $\alpha$ and NF1. Multiple studies have demonstrated that enhanced HNF3 $\alpha$ expression positively regulates PreS2/S promoter activity [26,27]. NF1 expression has been established as an essential factor for optimal S promoter activity [6]. Considering these key regulatory roles, the presence and interaction of these TFs are important contributing factors in the optimal activity of S promoter in the HC-04 model. Taking all this into consideration, low HBsAg production detected in $\mathrm{HuH}-6$, despite high $\mathrm{HNF} 3 \alpha$ expression, could be due to lack of NF1 expression, and the consequent absence of the critical interaction of these TFs.

Overall, this study unravels the significance of the existence of a certain TFs network and the high similarity of the TFs transcriptome profile to PHH in ensuring the efficacy of the transfection model for HBV genotype B replication and gene expression. These findings could lead to a more informed choice of transfection models for studying non-D genotypes.

Supplementary Materials: The following are available online at https:/ / www.mdpi.com/1999-491 5/13/3/524/s1, Figure S1: Liver enriched and Ubiquitous TFs expression in HepG2-hNTCP.

Author Contributions: Conceptualization: G.-H.L. and S.-G.L., Methodology, analysis and investigation: R.H.-H.C., A.K., Writing-Original Draft preparation: A.K., Writing-Review and Editing: A.K., T.M.-C.T., S.-G.L., G.-H.L. Supervision: S.-G.L., G.-H.L. All authors have read and agreed to the published version of the manuscript.

Funding: This work is supported by grant NMRC/TCR/014-NUHS/2015 from the National Medical Research Council under the Eradication of HBV TCR Program.

Institutional Review Board Statement: Not applicable.

Informed Consent Statement: Not applicable.

Data Availability Statement: Not applicable.

Acknowledgments: We would like to thank Tao Zhu (University of Science and Technology of China) and Stephan Urban (University Hospital Heidelberg) for providing L02 and HepG2-hNTCP cell line.

Conflicts of Interest: Author Seng Gee Lim, is on the advisory board of Gilead, Abbvie, Abbott, Roche, Springbank, Kaleido Biosciences, Arbutus. He received speaker honorarium from Gilead, Abbvie, Abbott, Roche. He has received research funding from Gilead, Abbott, Roche, Sysmex, Fibronostics, Merck. Other authors declare no conflict of interest.

\section{References}

1. Seeger, C.; Mason, W.S. Molecular biology of hepatitis B virus infection. Virology 2015, 479-480, 672-686. [CrossRef] [PubMed]

2. Arvey, A.; Tempera, I.; Tsai, K.; Chen, H.S.; Tikhmyanova, N.; Klichinsky, M.; Leslie, C.; Lieberman, P.M. An atlas of the Epstein-Barr virus transcriptome and epigenome reveals host-virus regulatory interactions. Cell Host Microbe 2012, 12, 233-245. [CrossRef] [PubMed]

3. Burley, M.; Roberts, S.; Parish, J.L. Epigenetic regulation of human papillomavirus transcription in the productive virus life cycle. Semin. Immunopathol. 2020, 42, 159-171. [CrossRef]

4. Mohd-Ismail, N.K.; Lim, Z.; Gunaratne, J.; Tan, Y.J. Mapping the Interactions of HBV cccDNA with Host Factors. Int. J. Mol. Sci. 2019, 20, 4276. [CrossRef]

5. Oropeza, C.E.; Tarnow, G.; Sridhar, A.; Taha, T.Y.; Shalaby, R.E.; McLachlan, A. The Regulation of HBV Transcription and Replication. Adv. Exp. Med. Biol. 2020, 1179, 39-69.

6. Quasdorff, M.; Hösel, M.; Odenthal, M.; Zedler, U.; Bohne, F.; Gripon, P.; Dienes, H.P.; Drebber, U.; Stippel, D.; Goeser, T.; et al. A concerted action of HNF4alpha and HNF1alpha links hepatitis B virus replication to hepatocyte differentiation. Cell. Microbiol. 2008, 10, 1478-1490. [CrossRef] 
7. Turton, K.L.; Meier-Stephenson, V.; Badmalia, M.D.; Coffin, C.S.; Patel, T.R. Host Transcription Factors in Hepatitis B Virus RNA Synthesis. Viruses 2020, 12, 160. [CrossRef] [PubMed]

8. Sekiba, K.; Otsuka, M.; Ohno, M.; Yamagami, M.; Kishikawa, T.; Suzuki, T.; Ishibashi, R.; Seimiya, T.; Tanaka, E.; Koike, K. Hepatitis B virus pathogenesis: Fresh insights into hepatitis B virus RNA. World J. Gastroenterol. 2018, 24, 2261-2268. [CrossRef]

9. Raney, A.K.; Easton, A.J.; Milich, D.R.; McLachlan, A. Promoter-specific transactivation of hepatitis B virus transcription by a glutamine- and proline-rich domain of hepatocyte nuclear factor 1. J. Virol. 1991, 65, 5774-5781. [CrossRef] [PubMed]

10. Ori, A.; Atzmony, D.; Haviv, I.; Shaul, Y. An NF1 Motif Plays a Central Role in Hepatitis B Virus Enhancer. Virology 1994, 204, 600-608. [CrossRef]

11. Raney, A.K.; Johnson, J.L.; Palmer, C.N.; McLachlan, A. Members of the nuclear receptor superfamily regulate transcription from the hepatitis B virus nucleocapsid promoter. J. Virol. 1997, 71, 1058-1071. [CrossRef]

12. Zhang, P.; Raney, A.K.; McLachlan, A. Characterization of functional Sp1 transcription factor binding sites in the hepatitis B virus nucleocapsid promoter. J. Virol. 1993, 67, 1472-1481. [CrossRef]

13. Spandau, D.F.; Lee, C.H. Repression of the hepatitis B virus enhancer by a cellular factor. J. Gen. Virol. 1992, $73,131-137$. [CrossRef] [PubMed]

14. Yan, H.; Zhong, G.; Xu, G.; He, W.; Jing, Z.; Gao, Z.; Huang, Y.; Qi, Y.; Peng, B.; Wang, H.; et al. Sodium taurocholate cotransporting polypeptide is a functional receptor for human hepatitis B and D virus. Elife 2012, 1, e00049. [CrossRef]

15. Ni, Y.; Lempp, F.A.; Mehrle, S.; Nkongolo, S.; Kaufman, C.; Fälth, M.; Stindt, J.; Königer, C.; Nassal, M.; Kubitz, R.; et al. Hepatitis B and D Viruses Exploit Sodium Taurocholate Co-Transporting Polypeptide for Species-Specific Entry into Hepatocytes. Gastroenterology 2014, 146, 1070-1083.e6. [CrossRef]

16. Fujise, K.; Nagamori, S.; Hasumura, S.; Homma, S.; Sujino, H.; Matsuura, T.; Shimizu, K.; Niiya, M.; Kameda, H.; Fujita, K. Integration of hepatitis B virus DNA into cells of six established human hepatocellular carcinoma cell lines. Hepato Gastroenterol. 1990, 37, 457-460.

17. Nagamori, S.; Fujise, K.; Hasumura, S.; Homma, S.; Sujino, H.; Matsuura, T.; Shimizu, K.; Niiya, M.; Kameda, H. Protein secretion of human cultured liver cells. Hum. Cell 1988, 1, 382-390. [PubMed]

18. Hasumura, S.; Sujino, H.; Nagamori, S.; Kameda, H. Establishment and characterization of a human hepatocellular carcinoma cell line JHH-4. Hum. Cell 1988, 1, 98-100. [PubMed]

19. Tsurimoto, T.; Fujiyama, A.; Matsubara, K. Stable Expression and Replication of Hepatitis B Virus Genome in an Integrated State in a Human Hepatoma Cell Line Transfected with the Cloned Viral DNA. Proc. Natl. Acad. Sci. USA 1987, 84, 444-448. [CrossRef]

20. Sells, M.A.; Chen, M.L.; Acs, G. Production of hepatitis B virus particles in Hep G2 cells transfected with cloned hepatitis B virus DNA. Proc. Natl. Acad. Sci. USA 1987, 84, 1005-1009. [CrossRef]

21. Sheen, I.S.; Tsou, Y.K.; Lin, S.M.; Lin, C.J.; Lin, C.C.; Hsu, C.W.; Chen, Y.C.; Chang, M.L.; Yeh, C.T. Nuclear HBcAg and histology activity index as independent predictors of the expression of singly spliced HBV-RNA. J. Viral Hepat. 2007, 14, 70-74. [CrossRef] [PubMed]

22. Günther, S.; Li, B.C.; Miska, S.; Krüger, D.H.; Meisel, H.; Will, H. A novel method for efficient amplification of whole hepatitis B virus genomes permits rapid functional analysis and reveals deletion mutants in immunosuppressed patients. J. Virol. 1995, 69, 5437-5444. [CrossRef] [PubMed]

23. Pollicino, T.; Belloni, L.; Raffa, G.; Pediconi, N.; Squadrito, G.; Raimondo, G.; Levrero, M. Hepatitis B virus replication is regulated by the acetylation status of hepatitis B virus cccDNA-bound H3 and H4 histones. Gastroenterology 2006, 130, 823-837. [CrossRef] [PubMed]

24. Li, J.; Lin, S.; Chen, Q.; Peng, L.; Zhai, J.; Liu, Y.; Yuan, Z. Inhibition of Hepatitis B Virus Replication by MyD88 Involves Accelerated Degradation of Pregenomic RNA and Nuclear Retention of Pre-S/S RNAs. J. Virol. 2010, 84, 6387-6399. [CrossRef]

25. Loeb, K.R.; Jerome, K.R.; Goddard, J.; Huang, M.-L.; Cent, A.; Corey, L. High-Throughput Quantitative Analysis of Hepatitis B Virus DNA in Serum Using the TaqMan Fluorogenic Detection System. Hepatology 2000, 32, 626-629. [CrossRef]

26. Chen, M.; Hieng, S.; Qian, X.; Costa, R.; Ou, J.-H. Regulation of Hepatitis B Virus ENI Enhancer Activity by Hepatocyte-Enriched Transcription Factor HNF3. Virology 1994, 205, 127-132. [CrossRef]

27. Cirillo, L.A.; Lin, F.R.; Cuesta, I.; Friedman, D.; Jarnik, M.; Zaret, K.S. Opening of Compacted Chromatin by Early Developmental Transcription Factors HNF3 (FoxA) and GATA-4. Mol. Cell 2002, 9, 279-289. [CrossRef] 